\title{
Comparison of Bioethanol Production by Candida molischiana and Saccharomyces cerevisiae from Glucose, Cellobiose, and Cellulose
}

\author{
Jianning Zheng, Abhishek Negi, Chanin Khomlaem, and Beom Soo Kim* \\ Department of Chemical Engineering, Chungbuk National University, Cheongju 28644, Republic of Korea
}

\author{
Received: April 9, 2019 \\ Revised: May 15, 2019 \\ Accepted: May 16, 2019 \\ First published online \\ May 24, 2019 \\ ${ }^{*}$ Corresponding author \\ Phone: +82-43-261-2372; \\ Fax: +82-43-269-2370; \\ E-mail: bskim@chungbuk.ac.kr \\ pISSN 1017-7825, eISSN 1738-8872 \\ Copyright@ 2019 by \\ The Korean Society for Microbiology \\ and Biotechnology
}

\begin{abstract}
Bioethanol has attracted much attention in recent decades as a sustainable and environmentally friendly alternative energy source. In this study, we compared the production of bioethanol by Candida molischiana and Saccharomyces cerevisiae at different initial concentrations of cellobiose and glucose. The results showed that C. molischiana can utilize both glucose and cellobiose, whereas S. cerevisiae can only utilize glucose. The ethanol yields were $43-51 \%$ from different initial concentrations of carbon source. In addition, different concentrations of microcrystalline cellulose (Avicel) were directly converted to ethanol by a combination of Trichoderma reesei and two yeasts. Cellulose was first hydrolyzed by a fully enzymatic saccharification process using $T$. reesei cellulases, and the reducing sugars and glucose produced during the process were further used as carbon source for bioethanol production by C. molischiana or S. cerevisiae. Sequential culture of T. reesei and two yeasts revealed that $C$. molischiana was more efficient for bioconversion of sugars to ethanol than S. cerevisiae. When $20 \mathrm{~g} / 1$ Avicel was used as a carbon source, the maximum reducing sugar, glucose, and ethanol yields were $42 \%, 26 \%$, and $20 \%$, respectively. The maximum concentrations of reducing sugar, glucose, and ethanol were 10.9, 8.57, and $5.95 \mathrm{~g} / 1$, respectively, at $120 \mathrm{~h}$ by the combination of T. reesei and C. molischiana from $50 \mathrm{~g} / 1$ Avicel.
\end{abstract}

Keywords: Bioethanol, Candida molischiana, Saccharomyces cerevisiae, Trichoderma reesei, Avicel

\section{Introduction}

As industry development accelerates and fossil fuels decline rapidly, energy demand continues to rise and extensive research has been done on alternative, sustainable and environmentally friendly energy sources. Among them, crop-based bioethanol is the most widely used biofuel with production of 106 billion liters in 2017 [1]. Abuse of arable land for bioethanol production has been a concern for many years. Therefore, the scientific community is working extensively to produce bioethanol using microorganisms from inexpensive wastes such as lignocellulose $[2,3]$. Their use can reduce greenhouse gas emissions by $30-85 \%$ compared to gasoline [4]. The agricultural wastes generated during or after the processing of crops are generally rich in lignocellulosic biomass. Lignocellulose consists of cellulose and hemicellulose firmly bonded to lignin [5]. Second-generation bioethanol is produced by saccharification of lignocellulosic biomass, followed by microbial fermentation and product recovery [6].

Saccharomyces cerevisiae strains are commonly used in the food industry and in the laboratory because they are easy to grow and genetically tractable. In addition, they are used as model organisms for studying eukaryotic cellular processes. They are comparatively superior to other fungi and bacterial strains for bioethanol production at an industrial level. They can withstand a wide $\mathrm{pH}$ range and optimal acidic $\mathrm{pH}$ is more effective in suppressing contamination-related problems [7, 8]. In addition, they are GRAS (generally regarded as safe) for human consumption [9]. Candida molischiana is one of the few yeast species capable of degrading cellobiose into glucose [10]. Geiger et al. [11] isolated a mutant strain with increased thermotolerance (up to $45^{\circ} \mathrm{C}$ ) compared to parent strain. Because C. molischiana has strong resistance to ethanol and heat, this yeast may be 
more effective when introduced into industrial cellulose ethanol plants [11].

Recently, high-efficiency biodegradation of cellulosic biomass through microbial co-culture or complex communities has been proposed [12]. S. cerevisiae was cocultured with other microorganisms for optimal bioethanol production in a shorter period of time [13]. In our previous study, Trichoderma reesei and C. molischiana were sequentially cultured to produce bioethanol directly from $\alpha$-cellulose [14]. In this study, microcrystalline cellulose (Avicel) was used as a carbon source and three fungal species, T. reesei, C. molischiana, and S. cerevisiae, were used for bioethanol production from cellulose. First, growth of C. molischiana and $S$. cerevisiae and their bioethanol production were compared at different initial concentrations of glucose and cellobiose as carbon sources. Direct production of bioethanol from Avicel was then carried out by a combination of T. reesei and C. molischiana or S. cerevisiae. Cellulose was hydrolyzed by a fully enzymatic saccharification process using T. reesei cellulases and the produced reducing sugars and glucose were further utilized for ethanol production by C. molischiana or S. cerevisiae. The yields and concentrations of the produced reducing sugar, glucose, and ethanol by different microbial combinations were compared from various initial concentrations of Avicel.

\section{Materials and Methods}

\section{Microorganisms}

Three fungal strains were used in this study. Trichoderma reesei RUT-C30 (KCTC 6968) and Saccharomyces cerevisiae (KCTC 7928) were procured from Korean Collection for Type Cultures (Daejeon, Korea). Candida molischiana (ATCC 2516) was procured from American Type Culture Collection (USA).

\section{Media and Cultivation}

The $T$. reesei stock culture was aseptically grown on potato dextrose agar (PDA) medium consisting of $24 \mathrm{~g} / 1$ potato dextrose broth and $20 \mathrm{~g} / \mathrm{l}$ agar and incubated at $30^{\circ} \mathrm{C}$ for 7 days until sporulation was sufficient and then stored at $4^{\circ} \mathrm{C}$. T. reesei preculture medium consisted of (per L): Avicel PH101 (Sigma-Aldrich) $10 \mathrm{~g}$, $\left(\mathrm{NH}_{4}\right)_{2} \mathrm{SO}_{4} 1.4 \mathrm{~g}, \mathrm{KH}_{2} \mathrm{PO}_{4} 2 \mathrm{~g}, \mathrm{CaCl}_{2} 0.3 \mathrm{~g}, \mathrm{MgSO}_{4} \cdot 7 \mathrm{H}_{2} \mathrm{O} 0.3 \mathrm{~g}$, $\mathrm{FeSO}_{4} \cdot 7 \mathrm{H}_{2} \mathrm{O} 5 \times 10^{-2} \mathrm{~g}, \mathrm{MnSO}_{4} \cdot 5 \mathrm{H}_{2} \mathrm{O} 1.56 \times 10^{-2} \mathrm{~g}, \mathrm{ZnSO}_{4} \cdot 7 \mathrm{H}_{2} \mathrm{O}$ $1.4 \times 10^{-2} \mathrm{~g}$, and $\mathrm{CoCl}_{2} \cdot 6 \mathrm{H}_{2} \mathrm{O} 2 \times 10^{-2} \mathrm{~g}$. The pre-culture was grown in a shaking incubator at $30^{\circ} \mathrm{C}, 200 \mathrm{rpm}$ for $48 \mathrm{~h}$ and inoculated into $(10 \% \mathrm{v} / \mathrm{v}) 250 \mathrm{ml}$ flasks containing $100 \mathrm{~mL}$ medium of different initial concentrations of Avicel (10, 20, 30, 40, and $50 \mathrm{~g} / \mathrm{l})$. The initial $\mathrm{pH}$ was adjusted to 7 using $3 \mathrm{~N} \mathrm{NaOH}$.

C. molischiana and S. cerevisiae stock cultures were aseptically cultivated in YM agar petri plates consisting of (per L): 3 g yeast extract, $3 \mathrm{~g}$ malt extract, $5 \mathrm{~g}$ peptone, $10 \mathrm{~g}$ glucose, and $20 \mathrm{~g}$ agar incubated at $30^{\circ} \mathrm{C}$ for 2 days and then stored at $4^{\circ} \mathrm{C}$. C. molischiana and S. cerevisiae pre-cultures were grown in YM broth in a shaking incubator at $30^{\circ} \mathrm{C}$ and $200 \mathrm{rpm}$ for $24 \mathrm{~h}$ and inoculated into $(5 \% \mathrm{v} / \mathrm{v})$ $250 \mathrm{ml}$ flasks containing $100 \mathrm{ml}$ medium of different initial concentrations of glucose or cellobiose $(20,50$, and $100 \mathrm{~g} / \mathrm{l})$. The initial $\mathrm{pH}$ was adjusted to 6 using $3 \mathrm{~N} \mathrm{NaOH}$. For sequential culture, T. reesei was first grown in $250 \mathrm{ml}$ flasks containing $100 \mathrm{ml}$ medium of the pre-culture medium with different initial concentrations of Avicel (10-50 g/l) in a shaking incubator at $30^{\circ} \mathrm{C}$, $\mathrm{pH} \mathrm{7,} \mathrm{and} 200 \mathrm{rpm}$. Then, $5 \mathrm{ml}$ of C. molischiana or S. cerevisiae culture was added to $100 \mathrm{ml}$ of $T$. reesei cultured medium after $84 \mathrm{~h}$ for initial Avicel concentrations of 10, 20, and $30 \mathrm{~g} / \mathrm{l}$ and after $120 \mathrm{~h}$ for initial Avicel concentrations of 40 and $50 \mathrm{~g} / \mathrm{l}$, respectively.

\section{Analytical Methods}

Growth (OD at $600 \mathrm{~nm}$ ) was measured using a UV-visible spectrophotometer (UV mini-1240, Shimadzu, Japan). Reducing sugar was measured by dinitrosalicylic acid (DNS) method [15]. Glucose and ethanol concentrations were measured by HPLC system (YL 9100, Young-Lin, Inc., Korea). Samples used for HPLC analysis were centrifuged and filtered through $0.2 \mu \mathrm{m}$ filters. Each sample was injected into a Biorad Aminex hpx-87h column (USA) at $55^{\circ} \mathrm{C}$ with a refractive index detector and was eluted from the column using a mobile phase of $5 \mathrm{mM} \mathrm{H}_{2} \mathrm{SO}_{4}$ at a flow rate of $0.6 \mathrm{ml} / \mathrm{min}$. One unit (U) of cellulase was defined as the amount of enzyme that produced $1 \mu \mathrm{mol}$ of reducing sugar (glucose equivalent) per min at $30^{\circ} \mathrm{C}$ and $\mathrm{pH} 7$ [16].

\section{Results and Discussion}

Bioethanol is one of the most suitable renewable, alternative energy sources to replace fossil fuels. In order to solve the energy crisis and promote its use, it is essential to reduce the production cost by using cheap substrate along with increasing production efficiency using suitable microorganisms. In this study, we investigated the growth of C. molischiana and $S$. cerevisiae at different initial concentrations of glucose and cellobiose $(20,50$, and $100 \mathrm{~g} / \mathrm{l})$ as carbon sources (Fig. 1). Growth of the yeast was quantified by optical density measurement (OD at $600 \mathrm{~nm}$ ). In the case of $C$. molischiana, the growth rate in glucose medium was slightly higher than in cellobiose medium, but the final OD was similar for both carbon sources (Fig. 1A). The maximum OD values for both carbon sources were 11-13, indicating that C. molischiana can grow well at various concentrations of glucose and cellobiose. In the case of $S$. cerevisiae, growth in medium containing 20 and $50 \mathrm{~g} / 1$ initial glucose concentration was similar to that of C. molischiana in glucose medium at the same concentration 

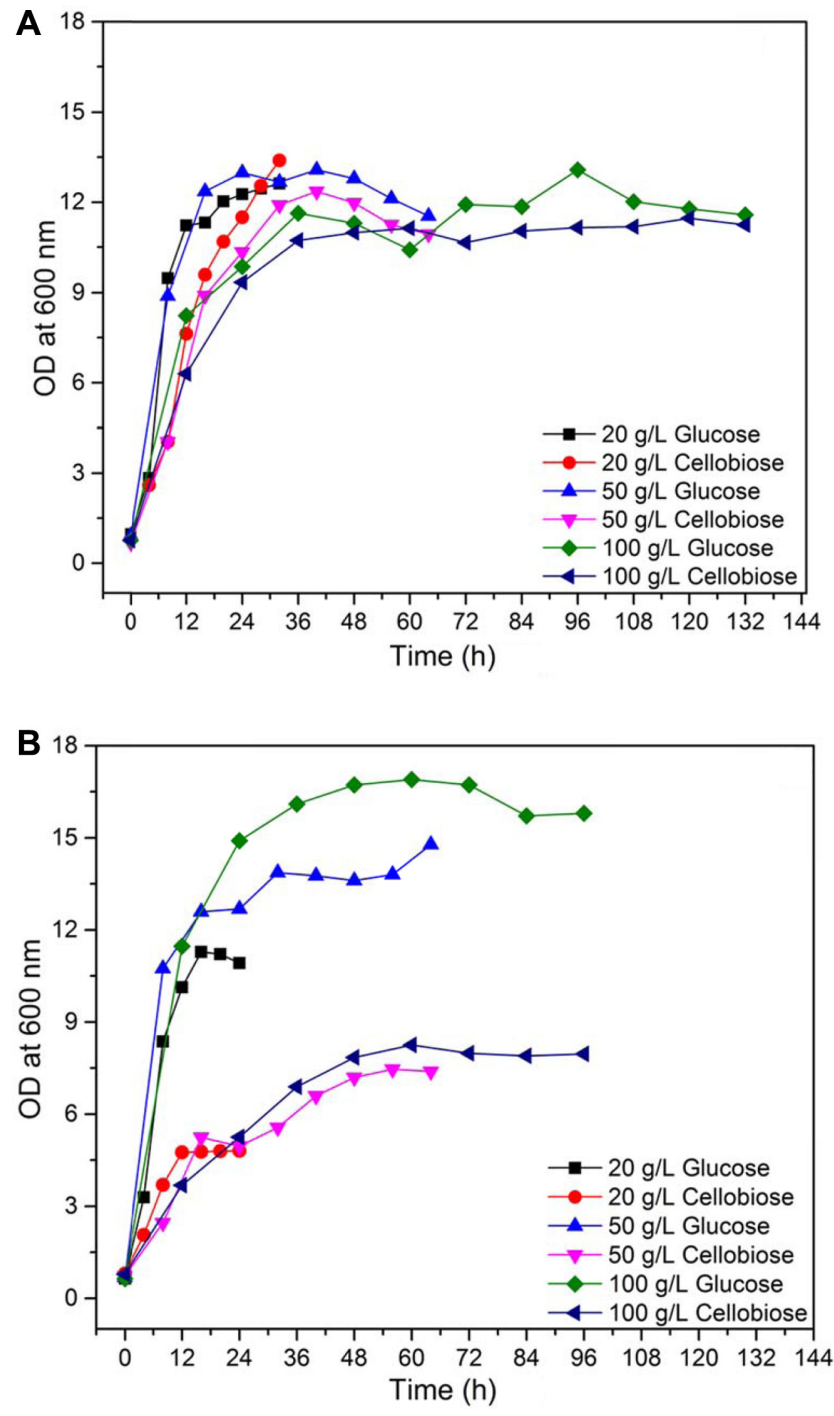

Fig. 1. Growth of (A) C. molishchiana and (B) S. cerevisiae using different initial concentrations of glucose and cellobiose.

(Fig. 1B). The final OD of $S$. cerevisiae culture at $100 \mathrm{~g} / 1$ initial glucose concentration was higher than that of C. molischiana culture and reached 16 after $36 \mathrm{~h}$. However, the growth of $S$. cerevisiae in cellobiose medium was remarkably slow and the final OD was much lower than that in glucose medium. This indicates that $S$. cerevisiae did not utilize cellobiose as carbon source and light growth occurred by consuming nutrients contained in YM media (yeast extract, malt extract, and peptone).

Figs. 2 to 4 show the sugar consumption profiles during the fermentation period of two yeast strains. Ethanol production by C. molischiana and S. cerevisiae was studied
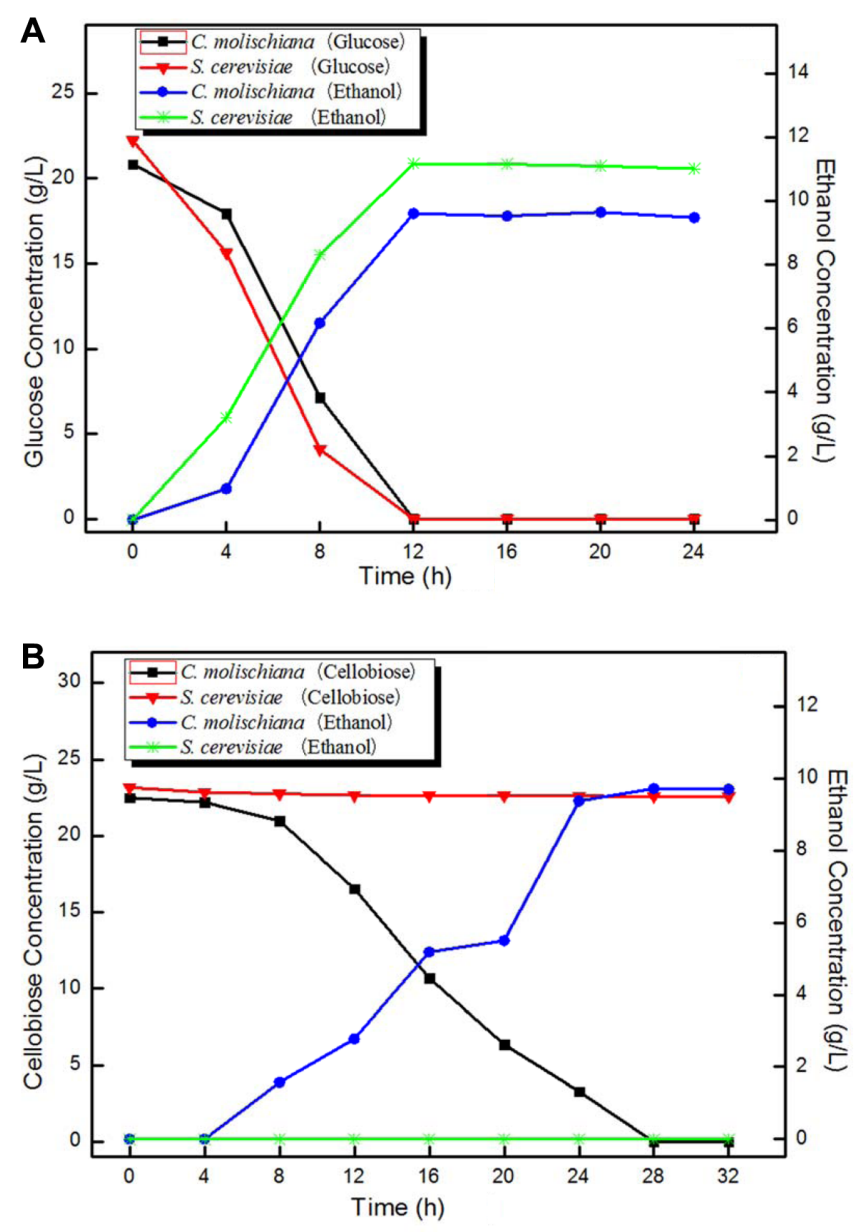

Fig. 2. Ethanol production by C. molischiana and S. cerevisiae using $20 \mathrm{~g} / 1$ of glucose and cellobiose.

(A) Glucose, (B) cellobiose.

using $20 \mathrm{~g} / 1$ of glucose or cellobiose as a carbon source (Fig. 2). Two yeast strains converted most of the glucose to ethanol (Fig. 2A). Glucose was completely consumed to produce ethanol within $12 \mathrm{~h}$ by C. molischiana and S. cerevisiae, with a yield of $46 \%$ and $50 \%$, respectively. Unlike C. molischiana which completed cellobiose consumption within $28 \mathrm{~h}$ with a yield of $43 \%$, S. cerevisiae was unable to metabolize cellobiose to ethanol (Fig. 2B). C. molischiana fermented glucose faster than cellobiose. Similar results were obtained when the substrate concentration was increased to $50 \mathrm{~g} / 1$ and $100 \mathrm{~g} / 1$ (Figs. 3 and 4). Fermentation time increased with increasing carbon source concentration. Table 1 summarizes bioethanol production yield from different initial concentrations of cellobiose and glucose. The ethanol yields were $43-51 \%$ from different initial 

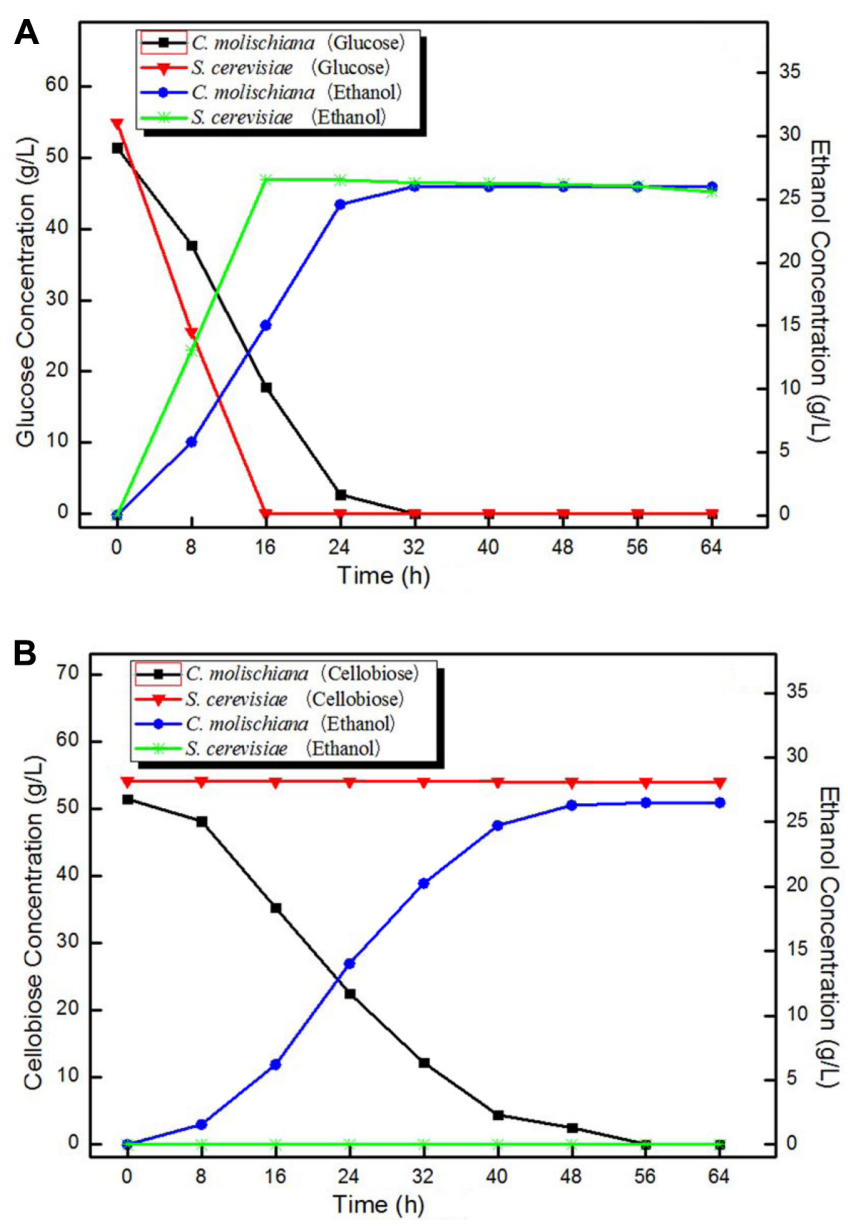

Fig. 3. Ethanol production by C. molischiana and S. cerevisiae using $50 \mathrm{~g} / 1$ of glucose and cellobiose.

(A) Glucose, (B) cellobiose.

concentrations of carbon source. High ethanol concentrations of $51 \mathrm{~g} / 1$ and $49 \mathrm{~g} / 1$ were obtained by C. molischiana from $100 \mathrm{~g} / 1$ glucose and cellobiose, respectively. S. cerevisiae produced $50 \mathrm{~g} / 1$ ethanol from $100 \mathrm{~g} / 1$ glucose, whereas

Table 1. Summary of ethanol production by C. molischiana and S. cerevisiae using different initial concentrations of glucose and cellobiose.

\begin{tabular}{lccc}
\hline Yeast & $\begin{array}{c}\text { Substrate } \\
\text { concentration } \\
(\mathrm{g} / \mathrm{l})\end{array}$ & $\begin{array}{c}\text { Ethanol yield } \\
\text { from glucose } \\
(\mathrm{g} / \mathrm{g})\end{array}$ & $\begin{array}{c}\text { Ethanol yield } \\
\text { from cellobiose } \\
(\mathrm{g} / \mathrm{g})\end{array}$ \\
\hline Candida & 20 & 0.46 & 0.43 \\
molischiana & 50 & 0.51 & 0.51 \\
& 100 & 0.51 & 0.49 \\
Saccharomyces & 20 & 0.50 & 0 \\
cerevisiae & 50 & 0.48 & 0 \\
& 100 & 0.50 & 0 \\
\hline
\end{tabular}
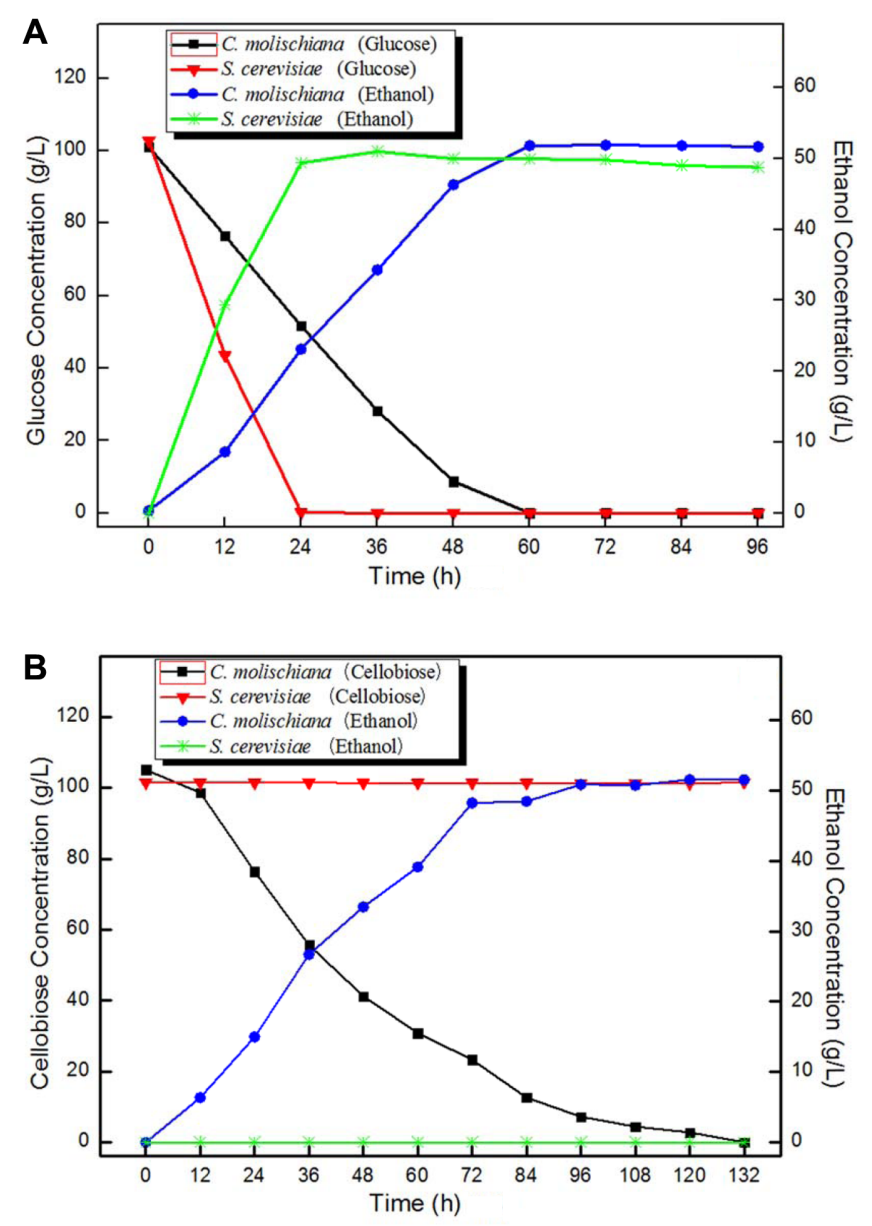

Fig. 4. Ethanol production by C. molischiana and S. cerevisiae using $100 \mathrm{~g} / 1$ of glucose and cellobiose.

(A) Glucose, (B) cellobiose.

ethanol was not detected from cellobiose.

Based on the basic characteristics of C. molischiana and $S$. cerevisiae, sequential cultivations of $T$. reesei and two yeasts were performed to produce ethanol from cellulose. T. reesei is known to be an overproducer of cellulolytic enzymes such as exoglucanases (cellobiohydrolases), endoglucanases, and $\beta$-glucosidases $[17,18]$. Direct production of ethanol from $\alpha$-cellulose by a microbial combination of T. reesei and $C$. molischiana has therefore been proposed [14]. Avicel was used as a source for cellulose in this study. Different initial concentrations of Avicel were used in the range of $10-50 \mathrm{~g} / 1$ to compare the ethanol yield from cellulose and determine the optimal initial substrate concentration (Figs. 5 to 9). Bioconversion of the substrate to ethanol by $T$. reesei and two yeasts was investigated for $132 \mathrm{~h}$ (Figs. 5 to 7 ) and $156 \mathrm{~h}$ (Figs. 8 and 9), respectively. The results showed that as the initial Avicel concentration 


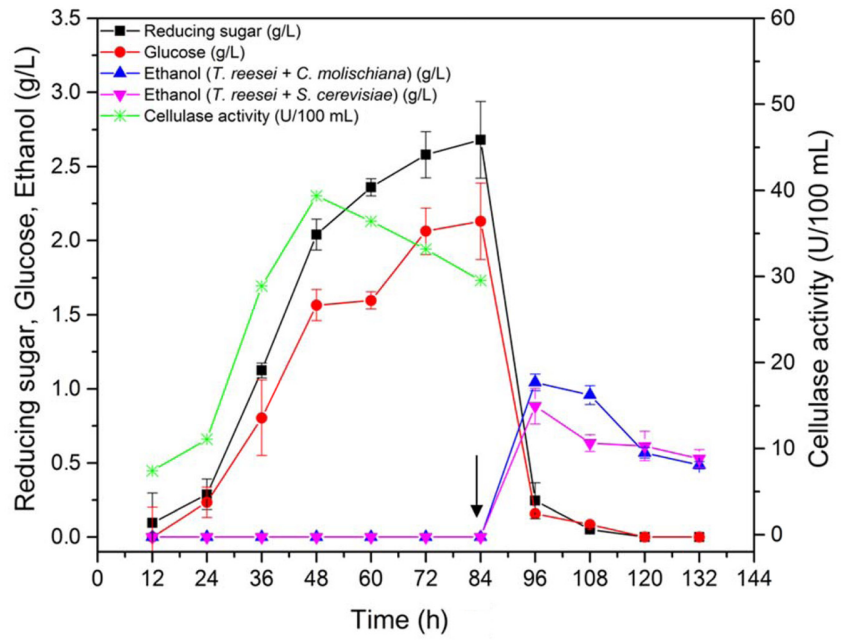

Fig. 5. Reducing sugar and glucose production by T. ressei and ethanol production by $C$. molischiana and $S$. cerevisiae using $10 \mathrm{~g} / 1$ Avicel.

Arrow indicates the inoculation time of yeast strains in the T. reesei cultured medium.

increased, more time was required to hydrolyze the cellulose. Table 2 summarizes the maximum concentrations and yields of reducing sugar, glucose, and ethanol. The ethanol yield by the combination of T. ressei and C. molischiana was relatively higher than that by the combination of T. ressei and S. cerevisiae. Therefore, it can be concluded that

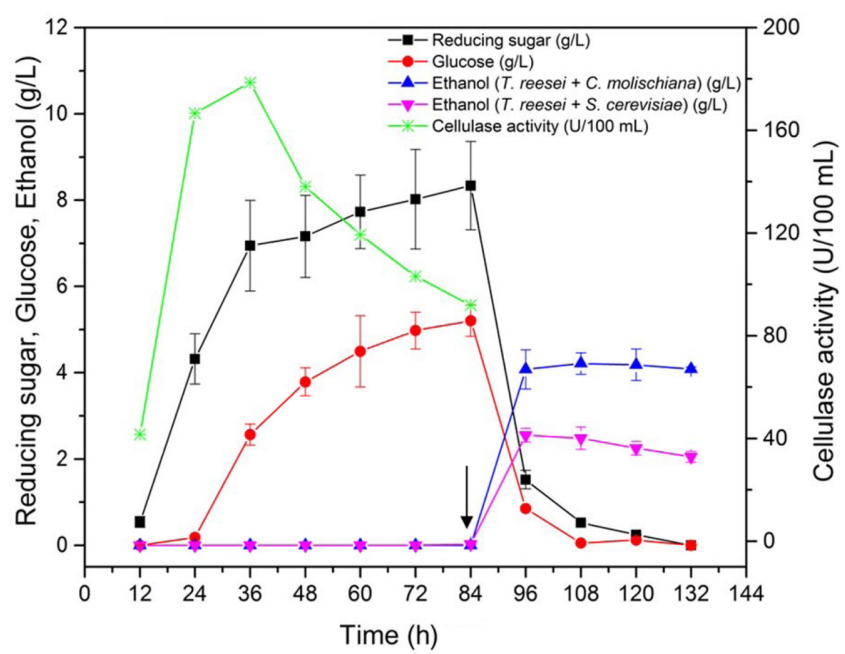

Fig. 6. Reducing sugar and glucose production by T. ressei and ethanol production by C. molischiana and S. cerevisiae using $20 \mathrm{~g} / 1$ Avicel.

Arrow indicates the inoculation time of yeast strains in the T. reesei cultured medium.

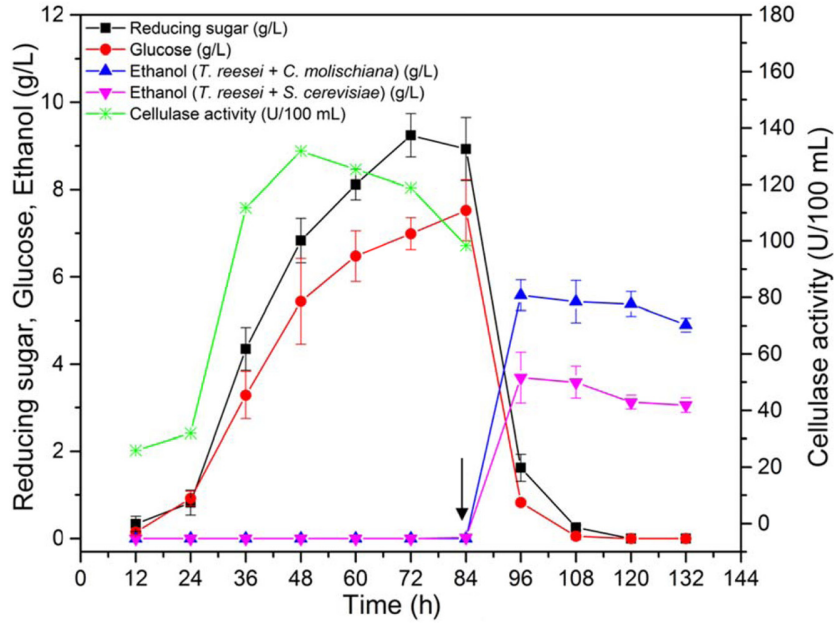

Fig. 7. Reducing sugar and glucose production by T. ressei and ethanol production by $C$. molischiana and S. cerevisiae using $30 \mathrm{~g} / 1$ Avicel.

Arrow indicates the inoculation time of yeast strains in the T. reesei cultured medium

C. molischiana is more efficient for the production of bioethanol from cellulose than $S$. cerevisiae.

On the other hand, maximum reducing sugar and glucose concentrations were obtained from fermentation of $50 \mathrm{~g} / 1$ Avicel and the maximum ethanol concentration was similar at 30, 40, and $50 \mathrm{~g} / 1$ Avicel (Figs. 7 to 9 and Table 2).

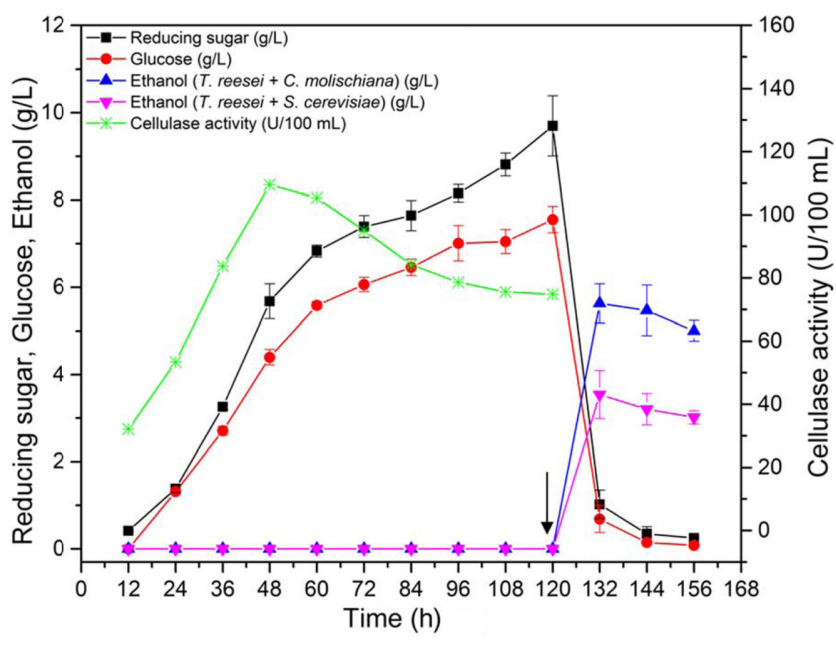

Fig. 8. Reducing sugar and glucose production by T. ressei and ethanol production by C. molischiana and S. cerevisiae using $40 \mathrm{~g} / 1$ Avicel.

Arrow indicates the inoculation time of yeast strains in the T. reesei cultured medium. 


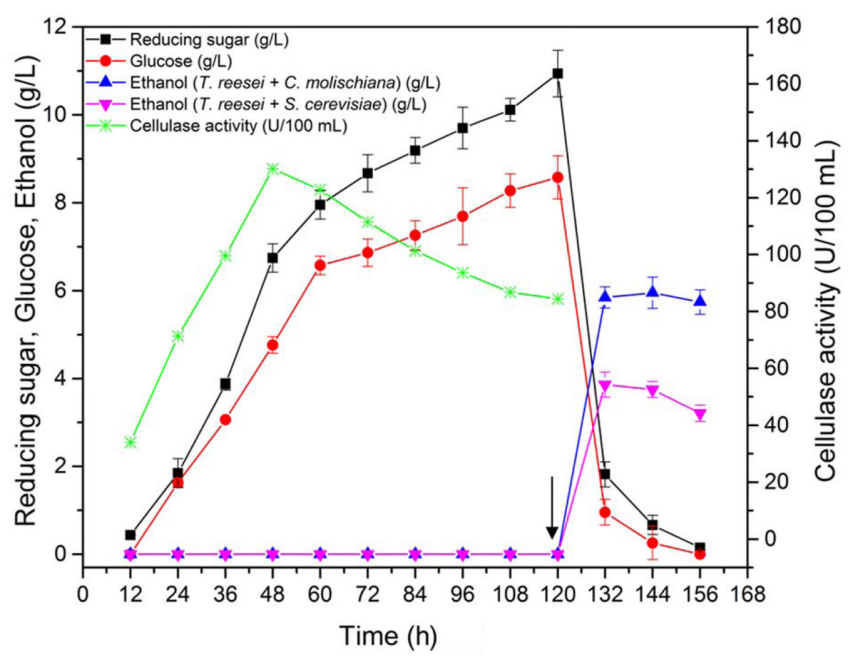

Fig. 9. Reducing sugar and glucose production by T. ressei and ethanol production by $C$. molischiana and $S$. cerevisiae using $50 \mathrm{~g} / 1$ Avicel.

Arrow indicates the inoculation time of yeast strains in the T. reesei cultured medium.

This means that high concentration of Avicel was not efficiently hydrolyzed by $T$. reesei used in this study. As the initial Avicel concentration increased beyond $20 \mathrm{~g} / 1$, the ethanol yield gradually decreased. Although the concentration of reducing sugar, glucose, and ethanol was not the highest at $20 \mathrm{~g} / \mathrm{L}$ Avicel, the final ethanol yield was highest at this Avicel concentration. Cellulase activities by $T$. reesei at different initial concentrations of Avicel were also calculated with time (Figs. 5 to 9). Maximum cellulase activities appeared 36-48 $\mathrm{h}$ after $T$. ressei inoculation. The highest cellulase activity was $180 \mathrm{U} / 100 \mathrm{ml}$ at $36 \mathrm{~h}$ when the initial Avicel concentration was $20 \mathrm{~g} / 1$ (Fig. 6). This indicates that the optimal initial Avicel concentration is $20 \mathrm{~g} / \mathrm{l}$ in terms of cellulase activity and ethanol yield.

The highest ethanol yield from $20 \mathrm{~g} / 1$ Avicel was $20 \%$ for the combination of T. ressei and C. molischiana and 13\% for the combination of $T$. ressei and $S$. cerevisiae. The ethanol yield obtained with the combination of $T$. ressei and C. molischiana is higher than the $15 \%$ previously obtained with the same combination from $\alpha$-cellulose [14]. Higher ethanol yield in this study can be related to the type of cellulose used. The weight average degree of polymerization (DPw) of Avicel PH101 was reported to be 200-240 anhydroglucose units (AGU) compared to 2140-2420 AGU for $\alpha$-cellulose [19]. $\alpha$-Cellulose is a solid residue of lignocellulose after extraction with strong alkali. In contrast, Avicel PH101 is further processed from $\alpha$-cellulose to change crystallinity, degree of polymerization, and porosity [19]. Similar results were obtained with Avicel as a substrate compared to other cellulosic substrates for the higher cellulase activity of T. reesei Rut C-30 [20], Sporocytophaga rnyxococcoides [21], and Saccharophagus degradans [22].

C. molischiana has been reported to ferment cellodextrins with a degree of polymerization of 2 to 6 to ethanol [23]. The higher ethanol yield by the combination of T. ressei and C. molischiana than by the combination of $T$. ressei and $S$. cerevisiae can be due to the additional consumption by C. molischiana of reducing sugars in addition to glucose produced by $T$. ressei, while $S$. cerevisiae can utilize only glucose. Although a high ethanol yield of $41 \%$ was reported using metabolically engineered strains of Clostridium thermocellum and Thermoanaerobacterium saccharolyticum [24], the ethanol yield $(20 \%)$ obtained in this study is similar to or higher than previously reported for wild-type strains [25-28]. It is noteworthy that C. molischiana and S. cerevisiae can perform ethanol fermentation in the presence of $T$. reesei. It suggests that there are not enough detrimental enzymes such as chitinase, which can have harmful effects on yeast to prevent alcohol accumulation [14]. By isolating the hyper cellulose producer and developing a highly productive bioreactor operation, direct ethanol production from cellulose may be possible by a microbial combination.

Table 2. Summary of reducing sugar, glucose, and ethanol production using different initial concentrations of Avicel.

\begin{tabular}{ccccccccc}
\hline $\begin{array}{c}\text { Avicel } \\
(\mathrm{g} / \mathrm{l})\end{array}$ & \multicolumn{2}{c}{ Reducing sugar } & \multicolumn{2}{c}{ Glucose } & \multicolumn{2}{c}{$\begin{array}{c}\text { Ethanol } \\
(\text { T. ressei }+ \text { C. molischiana })\end{array}$} & $\begin{array}{c}\text { Ethanol } \\
(\text { T. ressei }+ \text { S. cerevisiae })\end{array}$ \\
\hline & $\begin{array}{c}\text { Maximum conc. } \\
(\mathrm{g} / \mathrm{l})\end{array}$ & $\begin{array}{c}\text { Yield } \\
(\mathrm{g} / \mathrm{g})\end{array}$ & $\begin{array}{c}\text { Maximum conc. } \\
(\mathrm{g} / \mathrm{l})\end{array}$ & $\begin{array}{c}\text { Yield } \\
(\mathrm{g} / \mathrm{g})\end{array}$ & $\begin{array}{c}\text { Maximum conc. } \\
(\mathrm{g} / \mathrm{l})\end{array}$ & $\begin{array}{c}\text { Yield } \\
(\mathrm{g} / \mathrm{g})\end{array}$ & $\begin{array}{c}\text { Maximum conc. } \\
(\mathrm{g} / \mathrm{l})\end{array}$ & $\begin{array}{c}\text { Yield } \\
(\mathrm{g} / \mathrm{g})\end{array}$ \\
\hline 10 & 2.68 & 0.27 & 2.13 & 0.21 & 1.04 & 0.10 & 0.88 & 0.09 \\
20 & 8.34 & 0.42 & 5.20 & 0.26 & 4.08 & 0.20 & 2.55 & 0.13 \\
30 & 8.93 & 0.30 & 7.52 & 0.25 & 5.58 & 0.19 & 3.69 & 0.12 \\
40 & 9.70 & 0.24 & 7.55 & 0.19 & 5.63 & 0.14 & 3.54 & 0.09 \\
50 & 10.9 & 0.22 & 8.57 & 0.17 & 5.95 & 0.12 & 3.86 & 0.08 \\
\hline
\end{tabular}


In conclusion, this study demonstrated that the use of C. molischiana was superior to S. cerevisiae for bioethanol production from cellobiose or Avicel as a carbon source. Ethanol yield from glucose and cellobiose was $43-51 \%$ in aerobic environment. The optimal initial Avicel concentration for cellulase activity and ethanol production was $20 \mathrm{~g} / 1$. Maximum yields of reducing sugar, glucose, and ethanol were $42 \%, 26 \%$, and $20 \%$, respectively, using the combination of $T$. ressei and C. molischiana under this condition.

\section{Acknowledgments}

This research was supported by the National Research Foundation of Korea (NRF-2017R1A2B4002371) and the Brain Korea (BK21) Plus project.

\section{Conflict of Interest}

The authors have no financial conflicts of interest to declare.

\section{References}

1. REN21. Advancing the global renewable energy transition. Renewables 2018 global status report in perspective. 2018. Available online: http://www.ren21.net/wp-content/uploads/ 2018/06/GSR_2018_Highlights_final.pdf.

2. Kumar A, Kushal S, Saraf SA, Singh JS. 2018. Microbial biofuels: a solution to carbon emissions and energy crisis. Front. Biosci. (Landmrk Ed) 23: 1789-1802.

3. Olsson L, Hahn-Hagerdal B. 1996. Fermentation of lignocellulosic hydrolysates for ethanol production. Enzyme Microb. Technol. 18: 312-331.

4. Fulton L, Howes T, Hardy J. 2004. Biofuels for transport: an international perspective. pp. 13. International Energy Agency, Paris, France.

5. Sawant SS, Salunke BK, Tran TK, Kim BS. 2016. Lignocellulosic and marine biomass as resource for production of polyhydroxyalkanoates. Korean J. Chem. Eng. 33: 1505-1513.

6. Saini JK, Saini R, Tewari L. 2015. Lignocellulosic agriculture wastes as biomass feedstocks for second-generation bioethanol production: concepts and recent developments. 3 Biotech. 5:337-353.

7. Lin Y, Zhang W, Li C, Sakakibara K, Tanaka S. 2012. Factors affecting ethanol fermentation using Saccharomyces cerevisiae BY4742. Biomass Bioenerg. 47: 395-401.

8. Ortiz Muniz B, Carvajal Zarrabal O, Torrestiana Sanchez B, Aguilar Uscanga MG. 2010. Kinetic study on ethanol production using Saccharomyces cerevisiae ITV-01 yeast isolated from sugar cane molasses. J. Chem. Technol. Biotechnol. 85: 1361-1367.
9. Prasertwasu S, Khumsupan D, Komolwanich T, Chaisuwan T, Luengnaruemitchai A, Wongkasemjit S. 2014. Efficient process for ethanol production from Thai Mission grass (Pennisetum polystachion). Bioresour. Technol. 163: 152-159.

10. Freer SN. 1991. Fermentation and aerobic metabolism of cyclodextrins. Appl. Environ. Microbiol. 57: 655-659.

11. Geiger MR, Gibbons WR West TP. 2014. A thermostable Candida molischiana mutant capable of ethanol production at elevated temperatures. J. Pure Appl. Microbiol. 8: 1743-1748.

12. Olson DG, McBride JE, Joe Shaw A, Lynd LR. 2011. Recent progress in consolidated bioprocessing. Curr. Opin. Biotechnol. 23: 396-405.

13. Bhadana B, Chauhan M. 2016. Bioethanol production using Saccharomyces cerevisiae with different perspectives: Substrates, growth variables, inhibitor reduction and immobilization. Ferment. Technol. 5: 2.

14. Bu Y, Alkotaini B, Salunke BK, Deshmukh AR, Saha P, Kim BS. 2019. Direct ethanol production from cellulose by consortium of Trichoderma reesei and Candida molischiana. Green Process Synth. 8: 416-420.

15. Wen ZY, Wei L, Chen SL. 2004. Hydrolysis of animal manure lignocellulosics for reducing sugar production. Bioresour. Technol. 91: 31-39.

16. Peterson R, Nevalainen H. 2012. Trichoderma reesei RUT-C30thirty years of strain improvement. Microbiology 158: 58-68.

17. Maharjan A, Alkotaini B, Kim BS. 2018. Fusion of carbohydrate binding modules to bifunctional cellulase to enhance binding affinity and cellulolytic activity. Biotechnol. Bioprocess Eng. 23: 79-85.

18. Rana V, Eckard AD, Teller P, Ahring BK. 2014. On-site enzymes produced from Trichoderma reesei RUT-C30 and Aspergillus saccharolyticus for hydrolysis of wet exploded corn stover and loblolly pine. Bioresour. Technol. 154: 282-289.

19. Jäger $G, W u ~ Z$, Garschhammer $K$, Engel $P$, Klement $T$, Rinaldi R, et al. 2010. Practical screening of purified cellobiohydrolases and endoglucanases with $\alpha$-cellulose and specification of hydrodynamics. Biotechnol. Biofuels 3: 18.

20. Peciulyte A, Anasontzis GE, Karlström K, Larsson PT, Olsson L. 2014. Morphology and enzyme production of Trichoderma reesei Rut C-30 are affected by the physical and structural characteristics of cellulosic substrates. Fungal Genet Biol. 72: 64-72.

21. Vance I, Topham CM, Blayden SL, Tampion J. 1980. Extracellular cellulase production by Sporocytophaga myxococcoides NCIB 8639. J. Gen. Microbiol. 117: 235-241.

22. Sawant SS, Tran TK, Salunke BK, Kim BS. 2017. Potential of Saccharophagus degradans for production of polyhydroxyalkanoates using cellulose. Process Biochem. 57: 50-56.

23. Gondé P, Blondin B, Leclerc M, Ratomahenina R, Arnaud A, Galzy P. 1984. Fermentation of cellodextrins by different yeast strains. Appl. Environ. Microbiol. 48: 265-269.

24. Argyros DA, Tripathi SA, Barrett TF, Rogers SR, Feinberg LF, Olson DG, et al. 2011. High ethanol titers from cellulose 
by using metabolically engineered thermophilic, anaerobic microbes. Appl. Environ. Microbiol. 77: 8288-8294.

25. Liu YK, Yang CA, Chen WC, Wei YH. 2012. Producing bioethanol from cellulosic hydrolyzate via co-immobilized cultivation strategy. J. Biosci. Bioeng. 114: 198-203.

26. Panagiotou G, Topakas E, Moukouli M, Christakopoulos P, Olsson L. 2011. Studying the ability of Fusarium oxysporum and recombinant Saccharomyces cerevisiae to efficiently cooperate in decomposition and ethanolic fermentation of wheat straw. Biomass Bioenerg. 35: 3727-3732.
27. Park EY, Naruse K, Kato T. 2012. One-pot bioethanol production from cellulose by co-culture of Acremonium cellulolyticus and Saccharomyces cerevisiae. Biotechnol. Biofuels 5(1): 64.

28. Singh N, Mathur AS, Tuli DK, Gupta RP, Barrow CJ, Puri M. 2017. Cellulosic ethanol production via consolidated bioprocessing by a novel thermophilic anaerobic bacterium isolated from a Himalayan hot spring. Biotechnol. Biofuels 10: 73. 